Pesq. Vet. Bras. 29(11):887-893, novembro 2009

\title{
Aspectos epidemiológicos e clínicos da estefanofilariose em vacas leiteiras e comparação entre métodos de diagnóstico ${ }^{1}$
}

\author{
Vanessa Issuzu Miyakawa², Antonio Carlos Faria dos Reis ${ }^{3}$ e Júlio Augusto \\ Naylor Lisbôa ${ }^{*}$
}

\begin{abstract}
Miyakawa V.I., Reis A.C.F. \& Lisbôa J.A.N. 2009. [Epidemiological and clinical features of stephanofilariasis in dairy cows and diagnosis methods confrontation.] Aspectos epidemiológicos e clínicos da estefanofilariose em vacas leiteiras e comparação entre métodos de diagnóstico. Pesquisa Veterinária Brasileira 29(11):887-893. Departamento de Clínicas Veterinárias, Centro de Ciências Agrárias, Universidade Estadual de Londrina, Campus Universitário, Cx. Postal 6001, Londrina, PR 86051-990, Brazil. E-mail: janlisboa@uel.br

Stephanofilariasis is a worldwide disease caused by the nematode Stephanofilaria that determines skin lesions. In cattle, the chronic dermatitis is characteristic begining with papules that progress to nodules, alopecia and ulcers with crusts. Despite it's long time recognition, there are few studies and reports about this disease, specially in Brazil. This work was conducted in order to investigate epidemiological and clinical features of stephanofilariasis in dairy cows and to compare two methods for the diagnosis confirmation. Fifty-eight naturally affected dairy cows from seven herds located in Santana do Itararé, state of Paraná, and Itaberá, state of São Paulo, were studied from January 2006 through August 2008. Two methods for the diagnosis confirmation were compared using biopsied tissues from the border of the skin lesion: the histopathological examination $(n=24)$ and the direct sediment examination of an isotonic saline solution in which the tissue fragment remained soaked $(n=20)$. The prevalence was higher from December to March $(57 \%)$ and lactating cows were primarily affected (87,9\%). The cranial aspect of the fore mammary glands was the main site of the skin lesions $(96,7 \%)$, chiefly near the ventral midline $(55 \%)$. The characteristic wound was of circular shape, ulcerated with crusts and serosanguineous exudation. Chronic dermatitis with eosinophilic and mononuclaer cell infiltrates was the histopathologic change pattern present. The parasite was not detected in any histologic section examined. The direct sediment examination otherwise proved to be efficient for the diagnosis confirmation revealing the nematode adult and larval forms in all the specimens.
\end{abstract}

INDEX TERMS: Stephanofilariasis, Stephanofilaria sp., udder skin lesion, dairy cow, diagnosis.

RESUMO.- A estefanofilariose é uma doença mundialmente distribuída e caracteriza-se por lesões na pele causadas por nematódeo do gênero Stephanofilaria. Nos

\footnotetext{
${ }^{1}$ Recebido em 18 de fevereiro de 2009.

Aceito para publicação em 18 de junho de 2009.

Dissertação de Mestrado do primeiro autor.

2 Mestre em Ciência Animal, Universidade Estadual de Londrina (UEL). Endereço particular: Rua Vereador José Consani 126, Santana do Itararé, PR 84970-000, Brasil.

${ }^{3}$ Departamento de Medicina Veterinária Preventiva, Centro de Ciências Agrárias (CCA), UEL, Londrina, PR, Brasil.

${ }^{4}$ Departamento de Clínicas Veterinárias, CCA, UEL, Campus Universitário, Cx. Postal 6001, Londrina, PR 86051-990. * Autor para correspondência: janlisboa@uel.br
}

bovinos manifesta-se por uma dermatite crônica associada com erupção papular progredindo para nódulos, alopecia e ulceração crostosa. Apesar de reconhecida há muitos anos, há poucos estudos e relatos sobre a mesma. A literatura é particularmente escassa no Brasil. Esse trabalho teve como objetivos investigar aspectos epidemiológicos e clínicos da estefanofilariose em vacas leiteiras naturalmente acometidas e comparar dois métodos para a confirmação do diagnóstico, o exame histopatológico e o exame direto. Foram investigados aspectos clínicos relacionados à ocorrência natural da estefanofilariose em 58 vacas de leite de sete rebanhos criados nos municípios de Santana do Itararé, PR e de Itaberá, SP durante o período de janeiro de 2006 a agosto de 2008. Dois mé- 
todos foram comparados para confirmação do diagnóstico a partir de tecido colhido por biópsia da borda das lesões, o histopatológico $(n=24)$ e o exame direto do sedimento da solução salina isotônica na qual o tecido permaneceu embebido $(n=20)$. A maior prevalência ocorreu de dezembro a março $(57 \%)$ e a maioria das vacas era lactante $(87,9 \%)$. As lesões se localizavam nos quartos anteriores do úbere em seu aspecto cranial $(96,7 \%)$, principalmente próximo à linha média (55\%). A lesão típica tinha formato circular era ulcerada com crostas e exibia exsudato sero-sanguinolento. No exame histopatológico evidenciou-se uma dermatite crônica com infiltrado mononuclear e eosinofílico. A presença do parasita não foi detectada em nenhum dos cortes examinados. O exame direto possibilitou a demonstração do agente em todas as amostras examinadas, comprovando-se como um método eficiente para a confirmação do diagnóstico.

TERMOS DE INDEXAÇÃO: Estefanofilariose, Stephanofilaria sp., vaca leiteira, ferida cutânea na mama, diagnóstico.

\section{INTRODUÇÃO}

A estefanofilariose é uma doença mundialmente distribuída e caracteriza-se por lesões na pele causadas por nematódeo do gênero Stephanofilaria. É mais prevalente no verão, devido à maior proliferação de moscas, como Musca conducens e Haematobia irritans, consideradas vetores do parasita, e acomete várias espécies animais (Johnson et al. 1981).

Cinco espécies do gênero Stephanofilaria estão associadas a lesões na pele de bovinos: $S$. dedoesi identificada na Indonésia; S. stilesi nos EUA e na Rússia; S. kaeli na Malásia (Buckley 1937); S. assamensis na Índia e na Rússia (Pande 1936) e S. okinawaensis no Japão (Ueno \& Chibana 1977).

No Brasil há muito poucos relatos, e as lesões foram observadas na cabeça, na região escapular, no teto e no jarrete (Oba et al. 1977); próximas à cauda, na garupa, na coxa (Novaes et al. 1988) e na quartela (Novaes et al. 1990). São frequentes na pele da mama (Gava et al. 2006), principalmente nos quartos anteriores do úbere (Birgel et al. 1972, Miyakawa et al. 2007), e a doença é conhecida popularmente como úlcera da lactação.

Após a infecção o período pré-patente varia de 3 a 8 semanas (Hibler 1966). A lesão cutânea caracteriza-se inicialmente por uma dermatite, com erupção papular progredindo para nódulo, alopecia e úlcera crostosa com exsudação sero-sanguinolenta (Scott 1988, White \& Evans 2002). O prurido está frequentemente presente. Se não tratada corretamente a ferida persiste por longo período de tempo.

O diagnóstico presuntivo baseia-se no histórico e na avaliação da característica da lesão. A confirmação do diagnóstico depende da observação das formas adultas e/ou larvares do parasita por meio do exame histopatológico (Maxie 2007), e do raspado da ferida ou esfregaço que podem ser corados com Giemsa ou vermelho Congo
(Novaes 2005). A demonstração do nematódeo associado à lesão é, na maioria das vezes, frustrada em exames histopatológicos (Gava et al. 2006), o que dificulta muito a confirmação do diagnóstico.

Tendo em vista a escassez de informações sobre a doença, o presente trabalho tem por objetivos avaliar aspectos epidemiológicos e clínicos relacionados à estefanofilariose de ocorrência natural em fêmeas bovinas com aptidão para a produção de leite e comparar a eficiência de dois métodos confirmatórios do diagnóstico.

\section{MATERIAL E MÉTODOS}

O protocolo experimental foi aprovado pelo Comitê de Ética em Experimentação Animal da UEL (CEEA/UEL) sob o número de registro 61/06. Foram avaliados e acompanhados, de janeiro de 2006 a agosto de 2008,58 casos naturais de estefanofilariose em vacas pertencentes a sete propriedades produtoras de leite localizadas nos municípios de Santana do Itararé, PR, e de Itaberá, SP, distribuídas num raio aproximado de $60 \mathrm{~km}$. Nesses rebanhos a doença era endêmica.

As propriedades acompanhadas possuíam rebanhos com características raciais parecidas: HPB, Jersey e seus cruzamentos. Adotavam padrão de manejo nutricional relativamente comum caracterizado por dieta balanceada com concentrado e com pastejo rotacionado no verão (capim Mombaça e/ou capim Elefante Pioneiro) e silagem de milho e/ou sorgo, além de cana-de-açúcar com uréia no inverno. Mesmo nos meses de baixa precipitação pluviométrica os animais eram alimentados nos piquetes (rotação na área de piquetes para adubação natural). Em uma das propriedades o alimento era oferecido aos animais uma vez ao dia em um barracão. A ordenha mecanizada era realizada duas vezes ao dia.

As vermifugações eram mais freqüentes nas bezerras, as quais recebiam dois tratamentos até os 60 dias de vida e mais três doses até a puberdade. As vacas eram vermifugadas somente no momento da secagem, realizada 60 dias antes do parto. Não recebiam vermífugos durante todo o período de lactação. Os antihelminticos utilizados alternadamente eram a ivermectina, o albendazol, o levamisol e a moxidectina.

No período de duração do estudo, todos os animais acometidos pela enfermidade foram examinados e tiveram a evolução da sua doença acompanhada. Investigaram-se informações sobre as fêmeas acometidas (raça, idade, número de partos, estado produtivo, fase da lactação), os dados sobre o manejo das propriedades e a sazonalidade da doença considerando a distribuição dos casos pelos meses chuvosos do ano (dezembro a março), meses secos (junho a setembro) e meses de transição (abril, maio, outubro e novembro). Calcularam-se os índices de morbidade. Avaliaram-se as características das lesões cutâneas (número, localização, formato, área, aparência e histórico da evolução), suas possíveis complicações, recidivas e outras manifestações relacionadas às mesmas. A mensuração da ferida foi realizada com paquímetro, no primeiro exame físico. Por se tratarem, na sua grande maioria de feridas com aspecto circular, obtiveram-se duas medidas: o maior e o menor diâmetro, para se calcular o diâmetro médio. A área da ferida foi calculada aplicando-se a fórmula: área $\left(\mathrm{cm}^{2}\right)=\pi \cdot r^{2}$; sendo $\mathrm{r}$ o raio (metade do diâmetro médio calculado).

Foram colhidas amostras de tecidos adjacentes à borda das lesões cutâneas de 24 das vacas estudadas. Três fragmentos 
de tecido foram obtidos por biópsias da borda de cada lesão com auxílio de um "punch" (6 mm de diâmetro interno). Tal procedimento foi precedido pela limpeza prévia do local com álcool etílico a $70 \%$ e anestesia local infiltrativa com $0,5 \mathrm{~mL}$ de Lidocaína $1 \%$ (sem vaso constritor) em cada ponto de colheita. Cada fragmento era constituído de aproximadamente três partes do tecido aparentemente sadio e uma parte do tecido lesionado, com formato cilíndrico e tamanho aproximado de $6 \mathrm{~mm}$ de diâmetro e $10 \mathrm{~mm}$ de profundidade. Dois fragmentos foram direcionados para o exame histopatológico $(n=24)$ e o restante para o método de exame direto $(n=20)$.

Para o exame histopatológico foram utilizados os procedimentos rotineiros do laboratório de Anatomia Patológica Veterinária, do Centro de Ciências Agrárias, da Universidade Estadual de Londrina. Os fragmentos de tecido foram acondicionados e fixados em frascos contendo solução tamponada de formol a $10 \%$ e submetidos às técnicas de processamento tradicionais. Os blocos de parafina histológica contendo tecido cutâneo foram cortados em micrótomo rotativo com espessura de 3-5 $\mu \mathrm{m}$. Corou-se com hematoxilina e eosina.

Para o exame direto empregou-se o método preconizado por Ueno \& Gonçalves (1998), o qual se baseia na migração dos parasitas do tecido para a solução no qual este fica embebido. O fragmento tecidual foi mantido submerso em solução fisiológica ( $\mathrm{NaCl}$ 0,9\%) - 10 partes de solução para uma de tecido - em um recipiente plástico por no mínimo 3 horas em temperatura ambiente. Após a remoção do fragmento toda a solução do recipiente foi centrifugada (1.500rpm por $5 \mathrm{~min}$ ). Várias gotas do sedimento foram examinadas, entre lâmina e lamínula, ao microscópio óptico, para visualização das formas adultas e/ou das larvas do parasita.

Para o estudo dos aspectos epidemiológicos, as distribuições de frequências foram calculadas e a significância estatística verificada utilizando-se o teste de Qui-Quadrado. Estabeleceram-se medidas de tendência central e de dispersão para a área das lesões cutâneas, e a sua correlação com o tempo de evolução.

\section{RESULTADOS E DISCUSSÃO}

O coeficiente de morbidade variou consideravelmente entre os rebanhos e não se relacionou com o número de animais nos mesmos (Quadro 1). A propriedade número 1 , detentora da maior prevalência apresentava uma característica particular. Adotava um manejo de semiconfinamento para as vacas em lactação em um barra-

Quadro 1. Incidência de estefanofilariose em fêmeas bovinas de rebanhos produtores de leite criados nos municípios de Santana do Itararé, PR, e de Itaberá, SP, entre janeiro de 2006 e agosto de 2008

\begin{tabular}{|c|c|c|c|c|c|c|c|c|c|}
\hline $\begin{array}{c}\text { Reba- } \\
\text { nho }\end{array}$ & Fêmeas & $\begin{array}{l}06 \\
\text { oente }\end{array}$ & $\%$ & Fêmea & $\begin{array}{l}007 \\
\text { Doentes }\end{array}$ & $\%$ & Fêmea & $\begin{array}{l}08 \\
\text { oentes }\end{array}$ & \\
\hline 1 & 80 & 17 & 21,2 & 70 & 7 & 10 & 81 & 1 & 1,2 \\
\hline 2 & & 7 & 14,3 & & & 2,2 & & 0 & 0 \\
\hline 3 & 3 & 3 & 7, & 4 & 3 & 7,5 & & 4 & 8,5 \\
\hline 4 & & 1 & & & 2 & 1 & & 2 & 6,9 \\
\hline 5 & 156 & 2 & 1 & 16 & 3 & 1,8 & 17 & 0 & 0 \\
\hline 6 & 35 & 1 & 2,8 & & 0 & 0 & 32 & 2 & 6,2 \\
\hline 7 & 24 & 0 & 0 & 25 & 1 & 4 & 35 & 1 & 2,8 \\
\hline Total & 400 & 31 & 7,7 & 404 & 17 & 4,2 & 438 & 10 & 2,3 \\
\hline
\end{tabular}

cão que recebia pouca incidência de luz solar apesar de bem ventilado, com piso de concreto, umidade elevada e grande acúmulo de matéria orgânica (fezes e urina) em virtude da remoção infrequente dos dejetos. As vacas permaneciam no interior desse barracão cerca de cinco a seis horas por dia. A maior presença de moscas era evidente e consequente ao ambiente pouco higiênico, o que provavelmente contribuía para a disseminação da doença (Gründer 2005).

A incidência diminuiu de um ano para o outro e isso é particularmente evidente nos rebanhos 1 e 2 (Quadro 1). Como o manejo não foi modificado, de forma geral, devese atribuir a redução de novos casos à prática mais frequente e ao início mais precoce do tratamento de todos os animais acometidos com aplicações tópicas de triclorfon e/ou de ivermectina nas feridas (Miyakawa et al. 2006). Ainda que a população de vetores tenha se mantido, a morte das microfilárias com o tratamento empregado diminuiu a chance de infecção dos insetos e resultou em uma provável redução da transmissão para os hospedeiros definitivos (Smith 1986, Gründer 2005).

A maior prevalência ocorreu de dezembro a março (57\% dos casos), meses de maior precipitação pluviométrica (Fig.1). Nos meses secos do ano (junho a setembro) e nos meses de transição (abril, maio, outubro e novembro) a prevalência foi menor, $24 \%$ e $19 \%$, respectivamente $(p<0,05)$. Segundo Pal \& Sinha (1968) essa sazonalidade está relacionada à proliferação das moscas, vetor comprovado da doença (Hibler 1966, Khan 1983). O padrão de distribuição sazonal poderia ser o resultado da concentração de um maior número de parições em determinada época do ano, visto que as lesões são observadas predominantemente nas vacas em lactação (Miyakawa et al. 2007). Nos rebanhos acompanhados as parições se distribuíram de forma equilibrada pelos meses do ano, o que garante que esse fator não interferiu nos resultados.

A idade dos animais acometidos variou de 2 a 10 anos (média de 5 anos), sendo que $65,5 \%$ estavam entre 2 e 5 anos e 34,5\% entre 6 e 10 anos. Quanto ao número de parições (Fig.2), não houve diferença significativa entre a

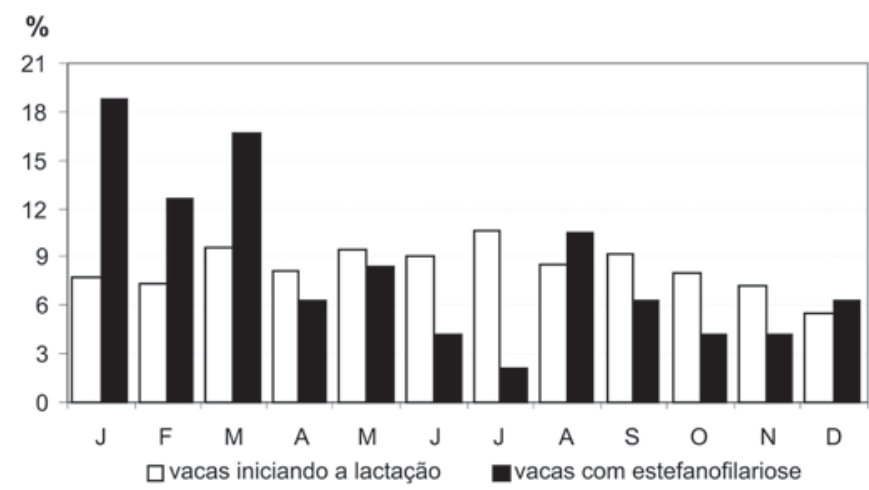

Fig.1. Distribuição, pelos meses nos anos de 2006 e 2007, dos casos de estefanofilariose em fêmeas bovinas de rebanhos produtores de leite criados nos municípios de Santana do Itararé, PR, e de Itaberá, SP, e das vacas da população em geral iniciando a lactação. 


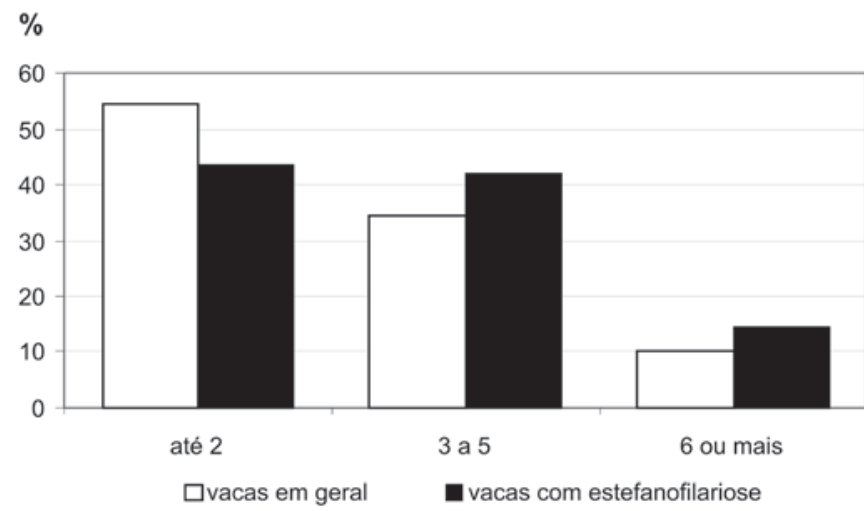

Fig.2. Distribuição das fêmeas bovinas da população em geral e das acometidas por estefanofilariose pertencentes a rebanhos produtores de leite criados nos municípios de Santana do Itararé, PR, e de Itaberá, SP, de acordo com o número de parições.

porcentagem de casos nas novilhas e vacas de até 2 partos $(43,1 \%)$ e nas de 3 a 5 partos $(43,1 \%)$, sendo menor nas de 6 a 9 partos $(13,8 \%)(p<0,05)$. Poderia ser considerado que a prevalência diminui nos animais mais veIhos em função da imunidade adquirida (Taylor et al. 2004). No caso da população de bovinos acompanhada, esse conceito não pode ser reforçado. A distinção da prevalência relacionada à idade é tendenciosa porque o número de vacas com mais de 8 anos, ou seja, na sexta lactação ou acima, é muito reduzido (Fig.2).

Considerando a raça, observou-se a seguinte distribuição: HPB ( $n=25 ; 43,1 \%)$, Jersey $(n=16 ; 27,6 \%)$ e cruzamentos entre as duas raças ( $n=17 ; 29,3 \%)$, sem distinção significativa $(p=0,401)$. Em relação ao estado produtivo, $87,93 \%$ estavam em lactação, $8,6 \%$ no período seco

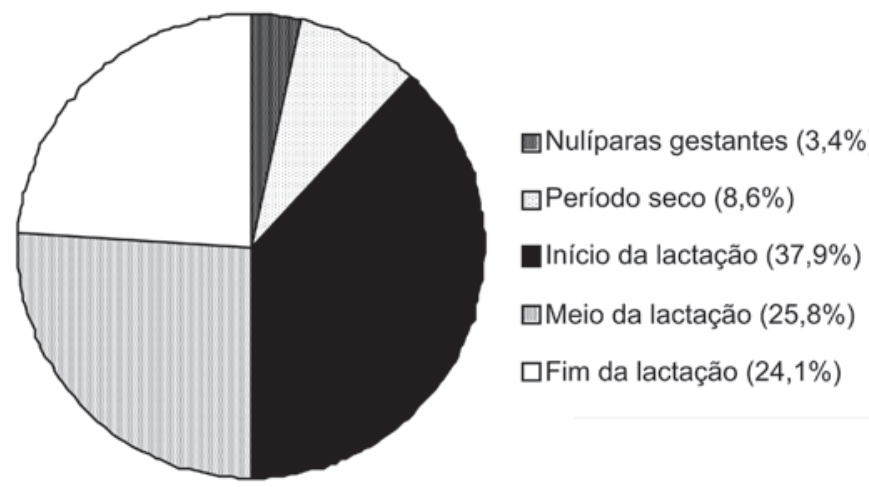

Fig.3. Distribuição dos casos de estefanofilariose em fêmeas bovinas de rebanhos produtores de leite criados nos municípios de Santana do Itararé, PR, e de Itaberá, SP, de acordo com a fase de produção.

e 3,4\% eram nulíparas com gestação avançada (Fig.3). Fica evidente pela observação desse resultado, que a denominação popular de "úlcera da lactação" está justificada. A ocorrência da doença está significativamente associada à lactação $(p<0,001)$, porém independe da fase particular da lactação $(p=0,432)$. Ou seja, o número aparentemente maior de vacas acometidas no início da lactação não é significativamente diferente daquele nos demais trimestres.

Deve-se considerar que diferentemente dos demais animais do rebanho, as vacas durante a lactação recebiam um manejo em lotes específicos, com acesso frequente às instalações para a ordenha e a permanência no interior das mesmas por 10 a 30 minutos após cada ordenha, ocasião em que ingeriam concentrado. Nessas condições estavam mais expostas às moscas e em contato mais provável com outras fêmeas portadoras da doença. O fato

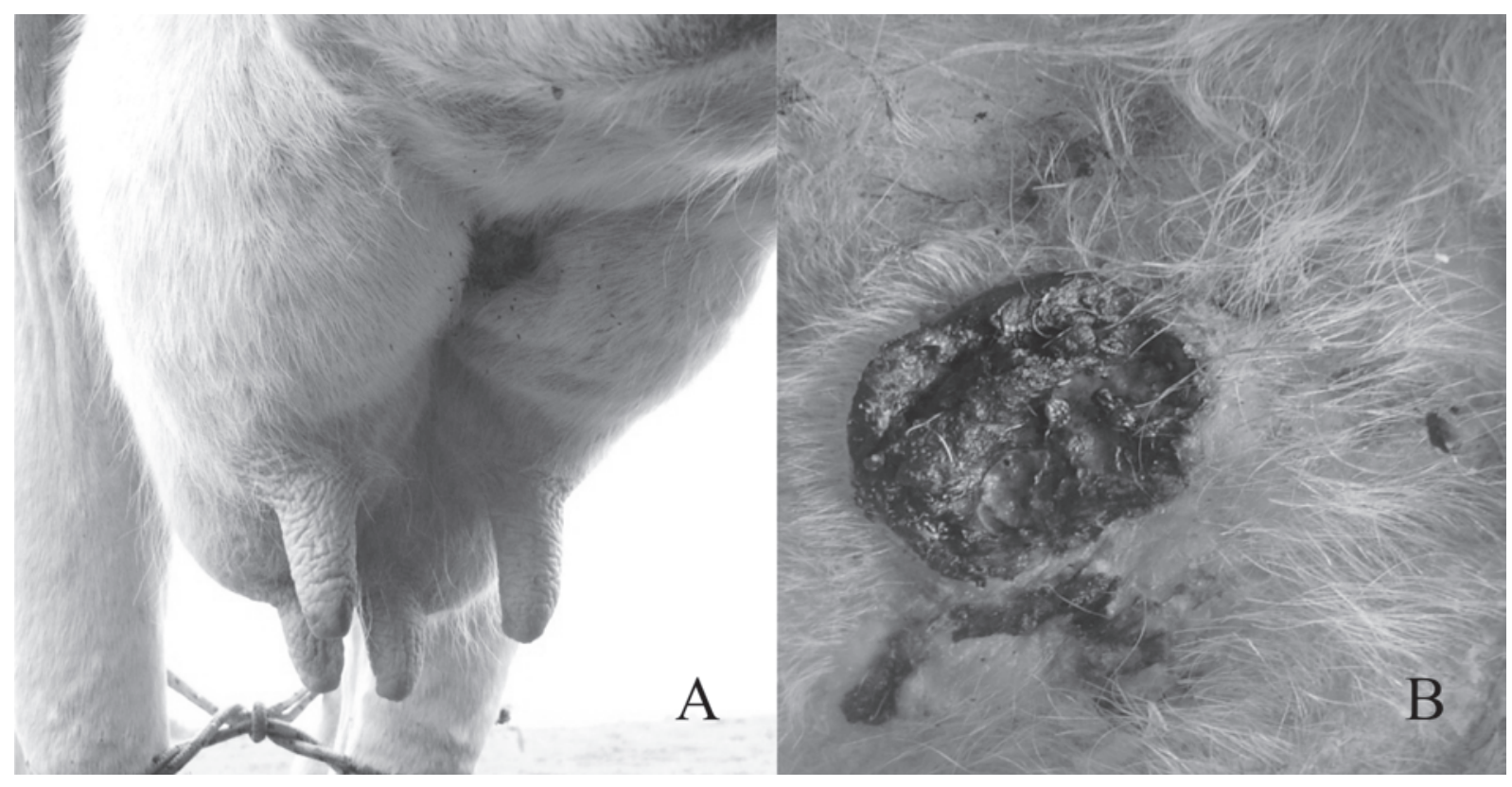

Fig.4. (A) Lesão em vaca leiteira causada por Stephanofilaria sp., localizada na linha média em posição cranial do úbere, (B) com formato circular, ulcerada com crostas e exsudato sero-sanguinolento. 
de não serem vermifugadas durante a lactação também pode aumentar o risco de desenvolvimento da doença.

A maioria das lesões se localizava na pele dos quartos anteriores do úbere $(96,7 \%)$, principalmente na linha média em posição cranial (55\%) (Fig.4). As demais lesões cutâneas localizavam-se na região cranial das glândulas mamárias anteriores direita $(26,7 \%)$ e esquerda (15\%). Nenhuma lesão foi observada na pele dos tetos, das glândulas posteriores ou da porção mais ventral entre os quatro quartos. Um dos animais apresentou lesão em posicionamento latero-dorsal no quarto anterior direito. Com exceção de um único caso em que a lesão se apresentava na prega do flanco esquerdo, não se observaram lesões cutâneas em qualquer outra localização nos animais estudados. Essa distribuição tão específica é fortemente compatível com o primeiro relato da doença no Brasil (Birgel et al. 1972), mas contraria as evidências apontadas em outros países (Buckley 1937, Pande 1936, Pal \& Sinha 1968, Das et al. 1974, Johnson et al. 1981, Chatterjee \& Chakrabarti 1983, Dies \& Pritchard 1985, Scott 1988, 2007, WatrelotVirieux \& Pin 2006, McGavin \& Zachary 2007). Somente Heidrich \& Renk (1967) afirmaram que as lesões são predominantes na pele do úbere e dos tetos. Fadzil et al. (1973) e Ueno \& Chibana (1977) descreveram lesões exclusivamente na pele dos tetos. Mesmo nas demais observações brasileiras as lesões não tinham localização tão particular (Oba et al. 1977, Novaes et al. 1988, 1990). Feridas predominantemente localizadas na pele do úbere foram apontadas também por Gava et al. (2006).

A grande maioria das vacas apresentava uma única lesão. Somente duas vacas exibiam duas lesões concomitantes, com $7-8 \mathrm{~cm}$ de distância entre elas. As feridas se iniciavam com alopecia e formação de pápula e nódulo. Em cerca de 72 horas adquiriam o seu aspecto característico: formato circular, ulcerada, com crostas e exsudato sero-sanguinolento de volume variável (Fig.4). A secreção purulenta estava presente em poucos casos (8\%). A presença de moscas atraídas pela ferida e o prurido constatado com as tentativas de lamber a ferida foram observações frequentes. Três lesões apresentaram miíase (5\%). Cinco vacas apresentaram ferida uma segunda vez 8-16 meses após o tratamento e a cura da primeira.

Os ordenhadores relataram atraso na ordenha devido à necessidade do tratamento das feridas e o estresse do animal na hora da manipulação da lesão, além de um maior acúmulo de sujidades e moscas na região, o que pode predispor ao surgimento de mastites, como relatam Heidrich \& Renk (1967) e Scott (1988).

A área das lesões observadas inicialmente foi de $9,52 \mathrm{~cm}^{2} \pm 7,66 \mathrm{~cm}^{2}$, variando de $0,78 \mathrm{~cm}^{2}$ a $44,16 \mathrm{~cm}^{2}$. Essa grande variação foi devida às diferenças no tempo de evolução dos casos, variando de 2 a 30 dias $(9,2 \pm 6,3$ dias). Quanto maior o tempo de evolução, maior o tamanho da lesão ( $r=0,896 ; p<0,0001)$.

O conjunto descrito das observações epidemiológicas e clínicas permite caracterizar, com mais detalhes e maior abrangência do que os relatos nacionais anteriores, como a doença se apresenta no Brasil. A localização tão específica e quase exclusiva da lesão cutânea na mama é uma característica marcante e um padrão que não é observado nos outros países em que a enfermidade foi relatada. Estudos futuros devem elucidar que espécie(s) de Stephanofilaria existe $(\mathrm{m})$ no país, o que talvez possa explicar a localização preferente das lesões.

O estudo histopatológico foi definido pela reação inflamatória dérmica acompanhada de reações da epiderme. Destacou-se a presença marcante de elementos polimorfonucleares eosinofilicos com distribuição dérmica (Fig.5). A camada epidérmica quando caracterizada mostrou-se de forma normal ou espessada em áreas periféricas da lesão do epitélio, que foi substituído por massa tecidual necrótica com restos celulares, hemácias e células inflamatórias. Estes resultados são, de forma geral, coerentes com outras descrições da doença (Loke \& Ramachandran 1966, Gava et al. 2006, Maxie 2007, McGavin \& Zachary 2007).

Considerando a periferia da lesão, na região epidérmica foram frequentes as observações de cristas interpapilares de espessura variada penetrando na derme, superficial ou mais profundamente. Nestas situações a epiderme apresentava maior celularidade (hiperplasia) dos extratos e figuras de mitose na camada germinativa além de amostras com maior espessamento da camada espinhosa (acantose). A epiderme adjacente às lesões necróticas mostrou reação típica de paraqueratose ortoqueratótica ou paraqueratótica. Quantidades variáveis de exsudato eosinofílico, debris celulares e células inflamatórias foram também verificadas nestas regiões próximas à ulceração e localizadas acima do extrato córneo. Na região dérmica os folículos pilosos, glândulas sebáceas e ductos de glândulas sudoríparas apresentaram-se normais. Elementos celulares mononucleares e eosinófilos foram também observados em pequeno número e normalmente posicionados em região superficial. Figuras de edema intracelular de ceratinócitos na camada espinhosa acon-

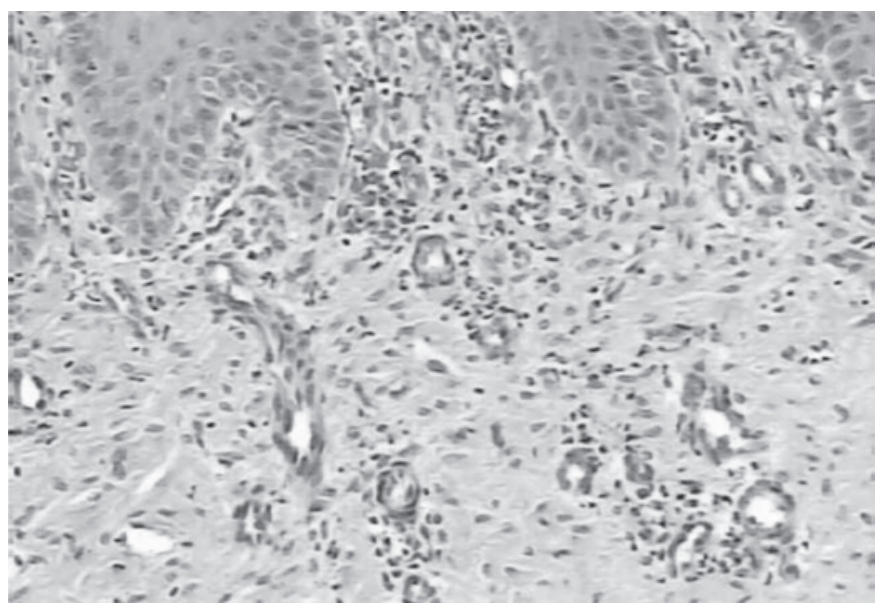

Fig.5. Reação eosinofílica discreta na região superficial da derme de uma vaca naturalmente acometida por estefanofilariose (HE, 20x). 
teceram de forma mais rara. A proliferação vascular em áreas adjacentes à ulcerada foi verificada em menor intensidade que na área desprovida de epitélio. Em somente um caso a reação inflamatória mostrou-se predominantemente constituída de elementos mononucleares, linfócitos e macrófagos, mas mesmo neste caso alguns elementos eosinofílicos foram identificados.

Considerando o centro da lesão, a região ulcerada da epiderme mostrava-se geralmente recoberta com fina ou grosseira camada crostosa contendo restos de células (debris celulares), além de variada quantidade de hemácias e elementos inflamatórios com citoplasma fortemente eosinofílico, em algumas vezes de natureza granulada. Formações de micro-abscessos na epiderme imediatamente vizinha à área de ulceração, bem como no epitélio de folículos pilosos foram verificados nos casos onde a exsudação leucocitária se apresentou de forma intensa. Elementos agrupados sem distinção de camadas (extratos) da epiderme mostraram-se presentes, em alguns casos estudados, na superfície erodida em posição superficial e envolvidos pela reação inflamatória e restos celulares. Ocasionalmente a região dérmica superficial e profunda, nas áreas centrais da lesão ulcerada, apresentou-se em grande extensão desprovida de folículos pilosos, glândulas sebáceas e ductos de glândulas sudoríparas. Tecido de granulação foi facilmente observado na derme formando a base da ulceração na maioria dos casos estudados. Neste tecido de granulação os vasos neoformados mostravam-se envolvidos por células inflamatórias mononucleares e eosinófilos ou somente por eosinófílos. Tal tecido de granulação foi verificado também em pequena extensão da derme apresentando revestimento de epiderme normal vizinha ao tecido ulcerado. A reação inflamatória com elementos eosinofílicos se extendia por vezes às papilas dérmicas mais próximas à região ulcerada.

Independentes de posição epidérmica, dérmica ou folicular, não foram observadas formas larvares ou adultas de Stephanofilaria spp, o que contraria o conceito tão freqüente nos livros-texto de que o exame histopatológico é um método eficiente para a confirmação da presença do parasita (Smith 1986, Scott 1988, 2007, Rosser Jr 1993, White \& Evans 2002). Apesar do grande número de tentativas em diferentes cortes histológicos o resultado foi frustrado. Gava et al. (2006) examinaram biópsias de 35 vacas acometidas e igualmente não conseguiram identificar a presença do nematódeo em nenhum corte histológico.

O exame direto (Ueno \& Gonçalves 1998), por outro lado, possibilitou a demonstração de formas adultas do agente em $100 \%$ das amostras examinadas (Fig. 6). A quantidade de parasita por amostra era grande e foi pos-

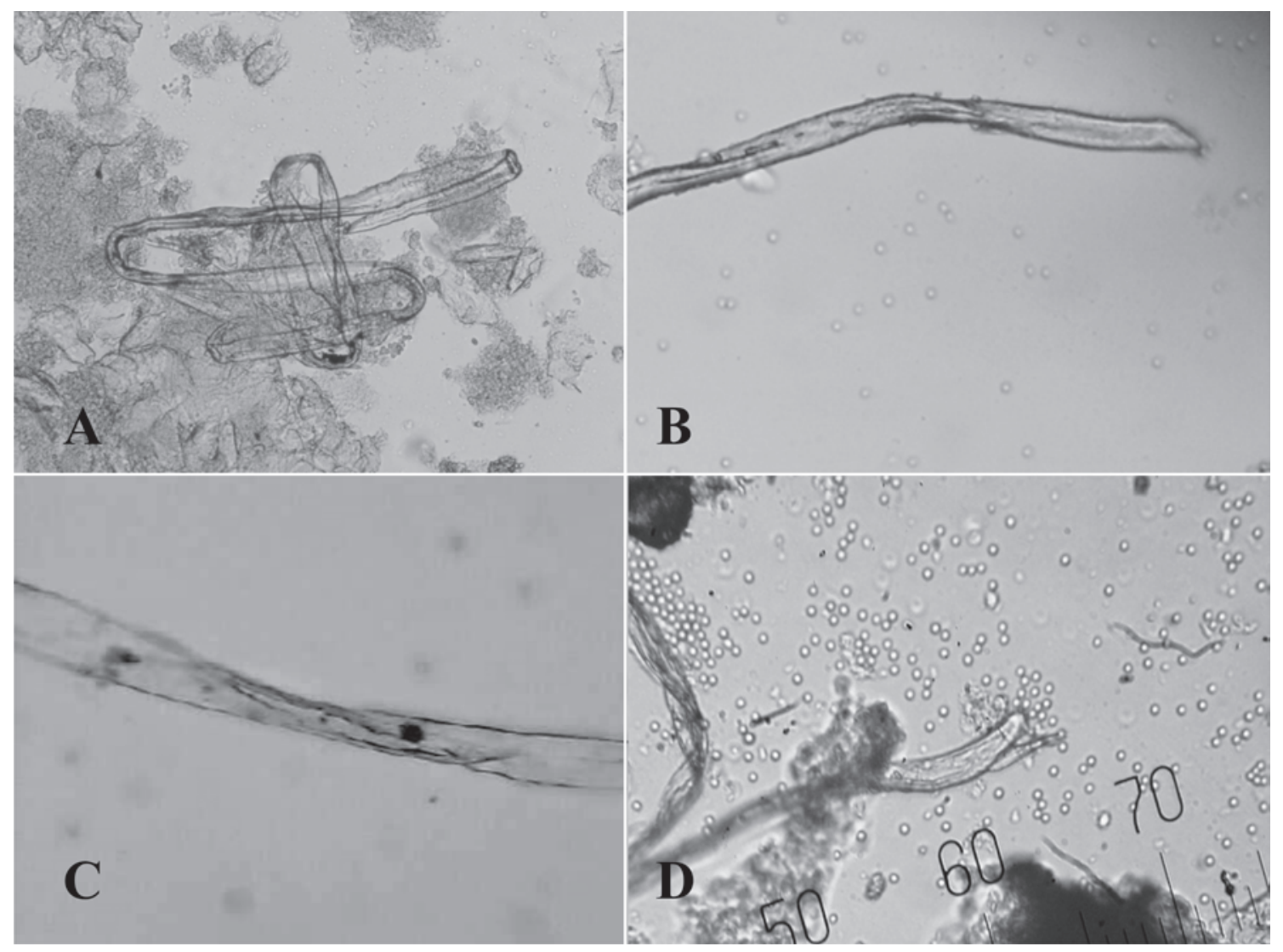

Fig.6. (A) Estefanofilárias observadas pelo exame direto do sedimento da solução fisiológica na qual o tecido biopsiado permaneceu embebido. (B) Algumas características morfológicas do parasita adulto como cabeça com espinhos, (C) microfilária no interior da fêmea, (D) espículo na cauda do macho. 
sível visualizar determinados aspectos morfológicos característicos do filarídeo, tais como: formato da boca e seus espinhos, formato do corpo e da cauda, espículo e presença de microfilárias no interior da fêmea. Quando possível os parasitas foram medidos e a variação do comprimento foi de $1,5 \mathrm{~mm}$ a $5,0 \mathrm{~mm}$. Trata-se, portanto, de um método confirmatório do diagnóstico eficaz, barato e de execução simples e fácil, requerendo unicamente um microscópio óptico para a sua realização.

Reafirmar a eficiência desse método de definição do diagnóstico tem grande importância prática em virtude de poder ser aplicado prontamente. Como conduta rotineira, o clínico veterinário estabelece o diagnóstico presuntivo de estefanofilariose com base no aspecto das lesões cutâneas e nas informações sobre a doença no rebanho. A resposta positiva ao tratamento contribui decisivamente, mas é comum que seja prolongado por mais do que 30 dias (Miyakawa et al. 2006). A conclusão do diagnóstico com a confirmação da presença do agente por meio de um procedimento exequível deve ser encorajada e difundida.

Em resumo a estefanofilariose é uma doença prevalente no verão, que acomete vacas lactantes sem predileção por idade e caracteriza-se por lesões cutâneas de formato circular, ulcerada com crosta e exsudato sero-sanguinolento, localizadas nos quartos anteriores do úbere. O exame histopatológico demonstra dermatite crônica característica com infiltrado mononuclear e eosinofílico, porém dificilmente pode revelar a presença do parasita. O exame direto do sedimento, baseado na migração do nematódeo do tecido para a solução fisiológica que o embebe, é um método eficaz para a confirmação do diagnóstico.

\section{REFERÊNCIAS}

Birgel E.H., Pereira P.C., Meirelles C.O.S., Amaral V. \& Araújo L.M. 1972. Úlcera da lactação, filariose provavelmente determinada por Stephanofilaria. Atualidades Vet. 1(2):56.

Buckley J.J.C. 1937. On a new species of Stephanofilaria causing lesions in the legs of cattle in the Malay Peninsula. J. Helminthol. 15(4):233242.

Chatterjee A. \& Chakrabarti A. 1983. Some uncommon lesions of Stephanofilarial dermatitis in cattle of West Bengal (India). Indian J. Anim. Health 22(1):67-70.

Das P.K., Tripathy S.B. \& Misra S.K. 1974. Studies on the pathoanatomy of the skin in Stephanofilaria assamensis Pande, 1936 infection in cattle. J. Anim. Sci. 45(8):543-545.

Dies K.H. \& Pritchard J. 1985. Bovine stephanofilarial dermatitis in Alberta. Can. Vet. J. 26:361-362.

Fadzil M., Chea T.S. \& Subramaniam P. 1973. Stephanofilaria kaeli Buckley 1937 as the cause of chronic dermatitis on the foot of a goat and on the ears and teats of cattle in west Malaysia. Vet. Rec. 92:316-318.

Gava A., Mezaroba S., Lucioli J., Furlan F.H. \& Traverso S.D. 2006. Stephanofilariose em bovinos no Estado de Santa Catarina: aspectos clínicos e lesionais. Resumos do 16은 Seminário de Iniciação Científica, Lages, Santa Catarina, p.95. (Resumo)

Gründer H.D. 2005. Stefanofilariosis, p.66-68. In: Dirksen G.T., Gründer H.D. \& Stöber M. (Eds), Medicina Interna y Cirúrgia del Bovino. Vol.1. $4^{\mathrm{a}}$ ed. Inter-Médica, Buenos Aires.

Heidrich H.J. \& Renk W. 1967. Diseases of the Mammary Glands of Domestic Animals. W.B. Saunders, Philadelphia. 371p.
Hibler C.P. 1966. Development of Stephanofilaria stilesi in the horn fly. J. Parasitol. 52(5):890-898.

Johnson S.J., Parker R.J., Norton J.H., Jaques P.A. \& Grimshaw A.A. 1981. Stephanofilariasis in cattle. Aust. Vet. J. 57:411-413.

Khan M.H. 1983. A note on the infestation of the stephanofilarial lesion by fly-maggots. Indian Vet. J. 60:232-233.

Loke Y.W. \& Ramachandran C.P. 1966. Histopathology of Stephanofilaria kaeli lesions in cattle. Med. J. Malaya 20(4):348.

Maxie M.G. 2007. Pathology of Domestic Animals. $5^{\text {th }}$ ed. Saunders Elsevier, Philadelphia. 899p.

Mcgavin M.D. \& Zachary J.F. 2007. Pathologic Basis of Veterinary Disease. $4^{\text {th }}$ ed. Mosby Elsevier, St Louis, Missouri. 1476p.

Miyakawa V.I., Reis A.C.F. \& Lisbôa J.A.N. 2006. Tratamento da estefanofilariose em vacas leiteiras: resultados preliminares. 33 Congresso Brasileiro de Medicina Veterinária, Cuiabá, MT. CD-ROM. (Resumo)

Miyakawa V.I., Reis A.C.F. \& Lisbôa J.A.N. 2007. Aspectos epidemiológicos e clínicos da estefanofilariose em vacas leiteiras. Arch. Vet. Sci. 12(Supl.):171-172.

Novaes A.P., Costa A.J.S., Barbosa R.T., Moreira D.P. \& Ruzza F.J. 1988. Dermatite ulcerosa em bovinos provocada por Stephanofilaria. Pesq. Agropec. Bras. 3(8):927-929.

Novaes A.P., Oliveira M.C.S. \& Moreira D.P. 1990. Stephanofilaria sp: associada a casos de pododermatite em bovinos leiteiros. Braz. Arch. Biol. Technol. 33(3):575-579.

Novaes A.P. 2005. Estefanofilariose e dermatite nodular ulcerativa em cão: relato de caso. Revta Educ. Contin. CRMV-SP 8(2):93-97.

Oba M.S.P., Sinhorini I.L., Novaes A.P., Costa A.J.S. \& Porto A.D. 1977. Stephanofilaria em bovinos do município de São Carlos, Estado de São Paulo. Anais $32^{\mathrm{a}}$ Conferência Anual da Sociedade Paulista de Medicina Veterinária, Pirassununga, São Paulo, p.12. (Resumo)

Pal A.K. \& Sinha P.K. 1968. Stephanofilaria assamensis as the cause of common chronic ulcerated growth at the base of the dewclaws in cattle in west Bengal. Indian Vet. J. 48:190-193.

Pande P.G. 1936. On the identity of the nematode worm recovered from humpsore of cattle in India. Indian J. Vet. Sci. Anim. Husbandry 6:346.

Rosser Jr E.J. 1993. Parasitic dermatosis, p.882-890. In: Howard J.L. Current Veterinary Therapy: Food animal practice. $3^{\text {rd }}$ ed. W.B. Saunders, Philadelphia.

Scott D.W. 1988. Large Animal Dermatology. W.B. Saunders, Philadelphia. $487 p$.

Scott D.W. 2007. Color Atlas of Farm Animal Dermatology. Blackwell Publ., Ames. 252p.

Smith J.P. 1986. Fly infestions, p.913-916. In: Howard J.L. (Ed.), Current Veterinary Therapy: Food animal practice. 2nd ed. W.B. Saunders, Philadelphia.

Taylor S.M., Hunter A.G. \& Andrews A.H. 2004. Ectoparasites, tick and arthropod-borne diseases, p.740-777. In: Andrews A.H., Blowey R.N., Boyd H. \& Eddy R.G. (Eds), Bovine Medicine: Diseases and husbandry of cattle. 2nd ed. Blackwell Publ., Ames.

Ueno H. \& Chibana T. 1977. Stephanofilaria okinawaensis n.sp. from cutaneous lesions on the teats of cows in Japan. Natl Inst. Anim. Health Q., Tokio, 17(1):16-26.

Ueno H. \& Gonçalves P.C. 1998. Manual para diagnóstico das helmintoses de ruminantes. $4^{\underline{a}}$ ed. Japan International Cooperation Agency, Tokyo. 143p.

Watrelot-Virieux D. \& Pin D. 2006. Chronic eosinophilic dermatitis in the scrotal area associated with stephanofilariasis infestation of charolais bull in France. J. Vet. Med. A Physiol. Pathol. Clin. Med. 53(3):150-152.

White S.D. \& Evans A.G. 2002. Parasitic skin diseases, p.1215-1222. In: Smith B.P. (Ed.), Large Animal Internal Medicine. $3^{\text {rd }}$ ed. Mosby, St Louis, Missouri. 